\title{
“NUNCA FALARAM DISSO NA ESCOLA...”: UM DEBATE COM JOVENS SOBRE GÊNERO E DIVERSIDADE
}

\author{
"NUNCA ME HABLARON DE ESO EN LA ESCUELA...": UN DEBATE \\ CON JÓVENES SOBRE GÉNERO Y DIVERSIDAD
“THEY NEVER TALKED ABOUT IT AT SCHOOL...": A DEBATE WITH YOUNGSTERS ABOUT GENDER AND DIVERSITY

\author{
Juliano Bonfim ${ }^{1}$ e Marcos Ribeiro Mesquita ${ }^{2}$
}

${ }^{1}$ Universidade Federal de Minas Gerais, Belo Horizonte/MG, Brasil

${ }^{2}$ Universidade Federal de Alagoas, Maceió/AL, Brasil

\begin{abstract}
RESUMO: O presente texto é parte das reflexões de uma pesquisa que analisou as formas de participação de jovens em discussões sobre gênero e sexualidade na instituição escolar. Aqui trazemos um recorte mais específico sobre as questões da diversidade sexual e de gênero e como as/os jovens a compreendem, a experienciam e percebem nas relações que estabelecem no cotidiano de sua escola. Utilizamos as estratégias de observação participante e conversas informais inspiradas na etnografia. Além disso, com a ferramenta de Grupos de Discussão, buscamos compreender os sentidos atribuídos por elas/es na relação estudada. Encontramos estudantes que, com diferentes culturas e inserções, têm enfrentado os desafios e questionado uma outra forma de ocupar os espaços dentro da escola e reivindicar o debate em torno das questões de gênero e sexualidade.

PALAVRAS-CHAVE: escola; jovens; gênero; diversidade sexual.
\end{abstract}

RESUMEN: Este trabajo se refiere a reflexiones de una investigación que analizó las formas de participación de jóvenes en discusiones sobre el género y la sexualidad en la institución escolar. Presentaremos un recorte más específico sobre las cuestiones de la diversidad sexual y género y cómo las/os jóvenes la comprenden, la experimentan y la perciben en las relaciones que establecen en lo cotidiano de su escuela. Utilizamos las estrategias de observación participante y conversaciones informales inspiradas en la etnografía. Además, con la herramienta de Grupos de Discusión, buscamos comprender los sentidos atribuidos por ellas en la relación estudiada. Encontramos estudiantes que, con sus diferentes culturas e inserciones, enfrentan los desafíos y cuestionan otra forma de ocupar los espacios dentro de la escuela y reivindicar el debate en torno a cuestiones de género y sexualidad.

PALABRAS CLAVE: Escuela; Jóvenes; Género; Diversidad sexual.

ABSTRACT: The present text is part of the reflections of a research that analyzed the ways of participation of youngsters in discussions about gender and sexuality in the school institution. Here we bring a more specific clipping on the issues of sexual diversity and gender, and how the youngsters understand it, experience it and notice it in the relations they establish in their school daily life. We used the strategies of participant observation and informal talks inspired by ethnography. Furthermore, we sought to understand the senses assigned by them in the relation studied with the Discussion Group tool. We found students of different cultures and inspections, who have faced the challenges and questioned another way of occupying the spaces in the school and claiming the debate on issues of gender and sexuality.

KEY WORDS: School; Youngsters; Gender; Sexual diversity. 


\section{Introdução}

Disputado por diferentes campos teóricos e por espaços institucionais e políticos, o conceito de gênero tem sido compreendido como uma ferramenta útil para pensarmos as relações sociais, as hierarquias e desigualdades que marcam as experiências de diferentes sujeitas/os ${ }^{1}$. De acordo com Scott (1995), esse termo foi utilizado inicialmente entre feministas americanas interessadas em enfatizar o caráter fundamentalmente social das distinções baseadas no sexo. Serviu para denunciar os discursos que naturalizavam as diferenças biológicas, buscando legitimar as desigualdades entre homens e mulheres. Assim, ao rejeitar o determinismo biológico do sexo, "o gênero se apresentou como uma categoria política radical, que recusava e rechaçava a fatalidade da natureza e colocava nas mãos de cada um e de cada uma os instrumentos de mudança das relações sociais entre os sexos" (Maia, 2007, pp. 134-135).

Judith Butler (2015) também enfatiza a distinção entre sexo e gênero e concebe este último como uma norma, uma construção social que carrega consigo significados sobre os corpos sexuados. Nesse sentido, nenhuma diferenciação poderá ser concebida como naturalmente determinada, ainda que haja regimes sociais que sustentam relações desiguais e hierárquicas que encontram na diferenciação sexual o respaldo.

Ao longo dos esforços, oriundos principalmente das lutas dos movimentos sociais, de questionar as relações hierarquizadas que atingem principalmente mulheres - sejam elas heterossexuais, lésbicas, bissexuais, travestis, transexuais - e homens gays, bissexuais e transexuais, nos últimos anos as discussões sobre gênero e seus desdobramentos no campo das sexualidades têm aumentado (Facchini, 2005; Machado, 2007). Expressa-se, portanto, como objeto de interesse de cientistas, gestoras/es, educadoras/es e sociedade civil, figurando instituições como o Estado, na formulação e implementação de políticas públicas, e a Igreja, trazendo inúmeras controvérsias durante debates públicos da Base Nacional Comum Curricular, dos Planos Nacional, Estaduais e Municipais de Educação, dividindo as opiniões nas Assembleias Legislativas e Câmaras de Vereadoras/es pelo Brasil com a polêmica "ideologia de gênero".

Apesar das discussões em torno da falaciosa “ideologia de gênero” terem se popularizado nos últimos anos, pesquisas ${ }^{2}$ demonstram que ela tem suas origens na década de 1990, por meio de um ativismo religioso, principalmente católico, interessado em combater ideias e avanços em torno do debate de gênero e sexualidade, em especial no campo da educação. No Brasil, desde 2014 o combate à "ideologia de gênero" tem sido utilizado por distintos grupos como estratégia de mobilização pela retirada das menções de gênero e orientação sexual dos documentos que regulamentam diretrizes e traçam estratégias para a construção de uma escola democrática. Com efeito, a expressão "ideologia de gênero" tem sido assimilada por diversos setores sociais e figurado debates outros, como por exemplo, com a proposição de projetos de lei como o "Escola Sem Partido" (ESP) em diversas casas legislativas pelo país.

Para Lionço (2016), “ideologia de gênero" é o argumento central na disputa fundamentalista pela política de educação. As/Os defensoras/es de projetos como o ESP acreditam que a função da escola é somente transmitir conhecimentos técnicos e, nesse sentido, professoras/es não podem emitir opinião de valor sobre os conteúdos que são responsáveis. Nesses moldes, é delegada à família a atribuição de formação moral, 
sexual e ética. A neutralidade, preconizada na proposição do ESP, impossibilita a construção de uma escola plural, crítica e democrática e não reconhece as/os sujeitas/os como atrizes/ atores transformadoras/es da realidade da escola.

Foi nesse cenário, nos bastidores das reuniões marcadas pelas disputas em torno desse debate, que o trabalho que possibilitou o presente artigo estava inserido. Este texto faz parte das reflexões de uma experiência de pesquisa que analisou as formas de participação de jovens nas discussões sobre gênero e sexualidades na instituição escolar. Neste artigo, discutiremos especificamente a questão da diversidade sexual e de gênero e como as/ os jovens a compreendem, a experienciam e a percebem nas relações que estabelecem no cotidiano de sua escola. Buscamos saber que narrativas constroem acerca de suas experiências em torno da diversidade.

O ambiente escolar que tomamos como foco de investigação é pensado como um local privilegiado e estratégico de discussão, principalmente se considerarmos a multiplicidade de visões das atrizes/atores envolvidas/os, assim como os tabus e interditos que marcam este debate (Abramovay, Castro, \& Silva, 2004). Segundo Louro (1997), é na escola, junto é claro a outros espaços sociais, onde são (re)produzidas as desigualdades, principalmente as relacionadas aos diferentes papéis ocupados por meninas e meninos, assim como à experiência da diversidade sexual.

A instituição escolar aparece como um dos principais espaços onde pessoas LGBTs declaram ter sofrido, ou ainda sofrem com as violências. Junqueira (2009a) denuncia que muitas vezes ela atua de modo a legitimar as hierarquias e relações de poder em um espaço que funciona sob a lógica da opressão e da violência a que jovens LGBTs estão submetidas/ os. Nesse sentido, muitas vezes o reconhecimento de lésbicas, gays, travestis e transexuais é negado, diante da (re)produção de um currículo marcado por dimensões que reforçam essas diferenças, provocando sofrimento e outros problemas que afetam diretamente suas trajetórias dentro da escola, como baixo rendimento e evasão, por exemplo (Junqueira, 2009b; Louro, 1997). Junqueira aponta que fenômenos discriminatórios como racismo e homofobia, por exemplo, fazem parte do cotidiano escolar como elementos que são ensinados dentro da escola e produz efeitos sobre todas/os, sejam estudantes ou não.

Nesse cenário, discursos que promovem humilhação, exclusão e/ou violência contra a população LGBT opõem-se aos direitos de cidadania, impedindo que algumas/uns desfrutem de tais direitos. O preconceito é formado, portanto, a partir das hierarquizações e dos marcadores sociais. Ele denuncia uma concepção de cidadania como direito e privilégio de umas/uns em detrimento do silenciamento de outras/os. A escola pode, então interferir positivamente ou não na vida das/os jovens, uma vez que é o lugar onde passam boa parte do dia e onde atribuem significados às suas vidas. Assim, a depender das relações ali construídas, algumas/uns delas/es podem não ter os significados necessários para definir e reconhecer como legítimas suas experiências sexuais, por exemplo (Torres, 2013).

Concordamos com Louro, Junqueira e outras/os autoras/es quando analisam a escola como um espaço que cria e reforça desigualdades de gênero e sexualidade. No entanto, compreendendo-a como um local em disputa, é nela também que várias experiências de solidariedade, afirmação e resistência são produzidas. É no ambiente escolar, que meninas e meninos têm suas primeiras experimentações e conversas sobre sexo, afetividade etc. É lá que começam a conhecer seus corpos, desejos, a conviver com a diversidade e a possibilidade de, a partir de suas trocas, questionar as normas de gênero e sexualidade existentes. 
Considerando a escola como um espaço de multiplicidade, mas também de adversidades, violências e conflitos, nos fazemos algumas perguntas: como as questões de gênero e sexualidade têm sido trabalhadas no interior da escola e que discursos e dinâmicas têm produzido? Como tem sido a participação das/os jovens nesse debate? Quais serão os significados atribuídos à escola por essas/es jovens no tocante à dimensão da diversidade? Refletir sobre esses e outros exemplos pode nos indicar o quanto a escola tem sido responsável por possibilitar ou não uma visão mais crítica e comprometida acerca desses temas junto às/aos estudantes.

\section{Metodologia}

Em nosso percurso de pesquisa buscamos nos situar a partir de uma perspectiva crítica da Psicologia (Neves \& Nogueira, 2004) que visa a romper com os paradigmas de uma ciência embasada em moldes duros, que não reconhecem a importância da interação no processo de construção do conhecimento. Nesse sentido, apostamos na horizontalidade das relações estabelecidas entre nós pesquisadores e de nossas/os interlocutoras/es e na transformação do cenário analisado por todas/os as/os envolvidas/os com o estudo (Lincoln \& Guba, 2006).

Nossos direcionamentos metodológicos foram possíveis graças às observações de campo feitas desde as primeiras idas à instituição. A divisão dos banheiros e vestiários, as atividades e jogos na educação física, os modos como alguns grupos ocupam determinados espaços lá dentro, as diferenças entre vestimentas de meninas e meninos, professoras e professores etc. nos revelavam as tramas do gênero e da sexualidade naquele espaço. A escola é um Instituto Federal localizado em um município da região metropolitana de uma capital nordestina. Por se tratar de uma cidade bastante central, também recebe estudantes oriundas/os de cidades vizinhas.

A instituição oferece ensino médio profissionalizante (na modalidade integrada), cursos do Programa de Integração da Educação Profissional com a Educação Básica na modalidade de jovens e adultas/os (Proeja), Pronatec, ensino superior de tecnologia e pósgraduação. Para ingressar no ensino médio as/os jovens passam por um processo seletivo e, por isso, apesar de haver uma reserva de vagas destinadas às cotas étnico-raciais, para pessoas com deficiências e vindas de escolas públicas, boa parte das/os estudantes é de classe média.

$\mathrm{Na}$ escola, encontramos um coletivo responsável por organizar uma série de debates voltados para as/os colegas da instituição, visando a discutir questões por vezes negligenciadas, indo desde um debate sobre a redução da maioridade penal, passando pela precarização dos serviços públicos, até machismo e LGBTfobias. Nesse contexto, os discursos e estratégias trazidas por elas/es para falar desses assuntos, foi algo importante para a realização de uma leitura mais aproximada de suas experiências.

Além das estratégias de observação participante e das conversas informais inspiradas na etnografia, apostamos na ferramenta metodológica de Grupos de Discussão (Mattos, 2012; Méndez, 2007) que possibilitou uma troca interessante sobre os sentidos atribuídos pelas/os jovens tanto da relação estudada, como de suas iniciativas. Os Grupos de Discussão, ou ainda grupos de reflexão, são ferramentas que permitem a quem pesquisa propor 
uma atividade ou tema para ser debatido pelas/os participantes. Nos grupos utilizamse situações disparadoras compostas por enunciados abertos que facilita a circulação dos temas abordados. De acordo com Mattos (2012), a discussão não é dirigida pela/o pesquisadora/or, esta/e se encarrega de introduzir perguntas e elementos que estimulem às/aos participantes falarem mais sobre o que pensam e até mesmo a elaborar uma fala coletiva sobre o assunto.

As situações auxiliam ainda na construção de categorias prévias sem, contudo, limitar e impossibilitar o surgimento de novas. Em nossos grupos pretendíamos fazer circular o diálogo sobre as temáticas do gênero e da sexualidade para que fossem construídas e compartilhadas ideias e saberes a respeito da diversidade no cotidiano escolar. Realizamos três encontros com sete das/os jovens que participavam das atividades organizadas pelo coletivo. Elas/es tinham idades compreendidas entre 17 e 19 anos e estavam no ensino médio. Cada encontro foi pensado a partir de um eixo norteador para a discussão. Esquematicamente, os eixos que nortearam os Grupos de Discussão foram: (a) saber como a experiência da diversidade sexual e de gênero é pensada e sentida por elas/es no espaço escolar; (b) compreender como as/os jovens entendem a experiência da diversidade sexual em suas relações cotidianas, seus anseios no campo da sexualidade e do gênero, bem como suas estratégias de enfrentamentos às diversas problemáticas por elas/es vividas.

A delimitação desses eixos demandava a realização de mais de um encontro para aprofundar as questões e oportunizar que todas/os pudessem falar. Para a apresentação neste artigo, fizemos um recorte mais especificamente do primeiro eixo, no entanto, as discussões do primeiro e do segundo se misturavam nas falas das/os estudantes. Cada encontro contou com a participação de um moderador e uma observadora da equipe de pesquisa, para facilitar a análise das impressões durante o grupo, bem como na reflexão sobre o alcance dos objetivos. Os grupos foram realizados nas dependências da escola, em salas de aula que estavam livres, e gravados em áudio, com o Termo de Consentimento Livre e Esclarecido (TCLE) assinado por elas/es.

Após a realização dos grupos, os áudios foram transcritos e utilizados para a apreciação dos resultados, onde utilizamos a ferramenta da Análise de Conteúdo (Campos, 2004), que propõe a sistematização e organização das falas em categorias que facilitam a interpretação. Campos nos alerta para uma análise que não seja excessivamente vinculada ao texto ou à técnica, de modo que prejudique a criatividade e capacidade intuitiva da/o pesquisadora/or e, ao mesmo tempo, não seja tão subjetiva a ponto de o texto funcionar como mero confirmador de suas ideias e valores.

Assim, tomamos cuidado para que as categorias de análise contemplassem a riqueza do conteúdo sem, contudo, esquecer de assumir que elas refletem nossas escolhas. Nesse sentido, corroborando Mattos, a presença da/o pesquisadora/or no resultado final é algo inquestionável, uma vez que a organização dos resultados só pode ser realizada evidenciando-se sua própria leitura do que aconteceu; é preciso admitir que, a partir dos usos desses métodos de análise, as falas das/os participantes do processo de pesquisa "se sobrepõem e se articulam ressignificando-se mutuamente" (Mattos, 2012, p. 179). A autora nos mostra ainda que a análise de narrativas de uma determinada pesquisa permite o entendimento de como sujeitas/os se posicionam em relação aos significados trazidos em suas falas e não apenas à identificação de quais seriam os significados públicos, compartilhados pelos grupos. 


\section{A escola e a diversidade}

Como apontamos, o debate de gênero e sexualidade está presente na escola, por mais que ela tente forçar uma visão neutra. Pensar a escola como um lugar de possibilidade das experiências da diversidade sexual e de gênero nos mostra que ela é obrigada, concordando ou não, a tratar desse debate. Diante dos avanços conquistados pelos movimentos sociais, educadoras/es têm optado por uma abordagem que percebe a pluralidade e as diferenças como características que constituem esse espaço.Tais abordagens são respaldadas por princípios e proposições curriculares elaboradas com a finalidade de orientar e normatizar aspectos fundamentais de uma educação cidadã, como a Lei de Diretrizes e Bases da Educação Nacional e os Parâmetros Curriculares Nacionais, por exemplo. Assim, por maior que seja a moralidade que rege as relações cotidianas e mantêm algumas de hierarquias, o ambiente escolar faz emergir outras experiências que aparecem para disputar posicionamentos e ideologias, revelando práticas que desarranjam as lógicas da instituição (Rancière, 1996).

Nos encontros com as/os meninas/os do grupo, buscamos compreender como elas/ es percebiam tal relação. Em uma das nossas conversas, Brunna ${ }^{4}$ relata como começou a perceber as relações da sexualidade e os padrões associados a ela no sistema educacional. A trama da nossa conversa era sobre o dia em que nos falamos pela primeira vez, no acalorado debate sobre o Plano Municipal de Educação (PME) e a polêmica "ideologia de gênero". Na ocasião, participamos de uma audiência pública organizada por um grupo de vereadoras/es para discutir a existência de uma cartilha contendo a suposta "ideologia de gênero" adotada para o PME. A audiência foi uma primeira convocação para as audiências que culminaram na retirada das menções de gênero e diversidade do documento, como aconteceu em outros municípios no Brasil durante o ano de 2015. Houve discussão entre integrantes de movimentos conservadores, religiosas/os e representantes de movimentos sociais feministas e LGBTs. Durante a sessão, várias/os dos parlamentares presentes enfatizaram que aquela era uma discussão já vetada pelo Congresso Nacional e que, por isso, precisava ser retirada dos planos municipais.

Voltando à conversa com Brunna, para a jovem, por mais que as pessoas não queiram falar sobre gênero e sexualidade na escola, elas estão fazendo isso a todo momento. Discutíamos sobre a educação infantil, quando ela trouxe uma reflexão que nos chamou a atenção:

Quando uma criança começa a estudar, entra na educação infantil, só tem professora, mulher, né? Eu só estudei com professores homens no ensino médio... Durante o ensino fundamental eram todas mulheres... as mulheres são responsáveis por cuidar, educar... (Brunna)

Tal constatação nos faz pensar que, na grande maioria das vezes, não nos damos conta dessas classificações de gênero que pertencem aos espaços sociais. A educação infantil, por exemplo, é marcada pela predominância de mulheres como educadoras. Quando encontramos um homem responsável por educar crianças, frequentemente questiona-se a capacidade que ele tem de realizar esse trabalho, sem contar os olhares suspeitos acerca de sua sexualidade e suas práticas de cuidado. Há uma divisão de gênero do trabalho que ilustra como alguns papéis são construídos e naturalizados de formas diferentes para 
mulheres e homens. A fala de Brunna evidencia como o trabalho ligado ao feminino é associado à esfera do cuidado e, nesse sentido, naturaliza que a educação, principalmente nesses primeiros anos de vida, seja de responsabilidade de mulheres.

A escola é um dos espaços onde vivenciamos nossas identidades de gênero, é onde somos colocadas/os em lugares organizados e determinados a partir de um molde que põe certos limites no que e como experienciamos. A construção daquilo que consideramos como feminino e masculino é realizada à medida que vamos diferenciando esses papéis designados para mulheres e para homens.

Dito isto, apresentaremos como a instituição escolar trata o debate da diversidade a partir das narrativas das/os jovens durante os Grupos de Discussão. Quando perguntamos se a escola possuía algum programa, disciplina, projeto ou política que trate das questões relacionadas ao gênero e à diversidade sexual, as/os jovens relataram que não há nenhum investimento por parte da instituição em promover algum debate sobre essas temáticas. Tendo em vista um modelo educacional cada vez mais presente, voltado para a formação técnica e profissional, na concepção de Léo, “a educação não é pra o aluno pensar, mas pra se qualificar pra um trabalho, pra aprender a reproduzir o conteúdo e pra ser mão de obra”. O jovem faz uma crítica a esse modelo limitado à reprodução e profissionalização das/os estudantes que acabam por não acessar e participar de discussões outras que falam de suas vidas, suas vivências. Num momento em que as universidades e instituições de ensino superior, por uma lógica do capital, limitam-se a um papel de prestação de serviços, como nos diz Chauí (2003) quando discute o que ela intitula de universidade operacional, a fala de Léo assume um tom de crítica, mas também de convocação para a construção de um outro modelo educacional em que esteja no centro a produção de um conhecimento e formação críticas.

No debate citado anteriormente, ouvimos falas de diversas/os vereadoras/es com uma visão da educação apenas como um processo de qualificação de mão de obra e preparação para o mercado de trabalho, onde dimensões de gênero e sexualidade, por exemplo, devem ser assuntos tratados em outras instituições, como a família e a Igreja. Castro (2012) aponta, no entanto, que a adesão das/os jovens ao projeto escolar abre a possibilidade para questionarmos o papel de transmissão de conhecimento e informação empreendido por muitas escolas. Quando elas se abrem para outras experiências para além do aspecto de mercado buscando inserir outros elementos e dimensões das vidas das/os estudantes, como esporte, sociabilidade e sexualidade, por exemplo, reinventam o seu cotidiano.

Embora não exista um espaço oficial, um programa específico para o tratamento desses temas, as práticas pedagógicas nos mostram quais são os roteiros seguidos por professoras/es e estudantes dentro dos espaços da instituição. E, nesse sentido, existem algumas/uns professoras/es aliadas/os que auxiliam na democratização e no reconhecimento da diversidade sexual, de gênero e cultural a partir das suas aulas e/ou das suas relações com as/os alunas/os dentro e fora da escola. A própria direção de ensino se coloca aberta para que as/os jovens possam realizar os debates nas dependências do instituto. Contudo, quando discutimos sobre a diversidade sexual e de gênero, a partir das situações disparadoras, elas/es pontuaram que muitos dos temas tratados nos grupos de discussão nunca foram sequer citados durante as aulas que discutiram sobre sexualidade (na disciplina de biologia) e que muito provavelmente as/os professoras/es não estariam preparadas/os para lidar com questões que fogem à cis-heteronormatividade ${ }^{3}$. 
Léo: ... a educação que é passada é uma educação padronizada, heterossexual...

Brunna: E o legal dessas situações que você trouxe é o despreparo dos educadores dentro dessas escolas, que a gente vai assemelhando com o que a gente tem aqui dentro da nossa instituição, um despreparo total em relação a isso, a diversidade... não sabem nem o que é que seria uma trans lésbica.

Léo: Nunca falaram disso na escola...

Brunna: Se a gente ficasse só aqui, com o que a gente aprende na escola a gente nunca ia saber que existia uma transexual lésbica.

Léo: A biologia é também só voltada pra questão machista e LGBTfóbica. Não fala de um sexo diferente do que é "normal", não fala que a mulher também goza...

A necessidade de um trabalho amplo de formação continuada que enfoque o acolhimento das/os estudantes no que concerne às demandas de gênero e sexualidade, nos parece imprescindível. O currículo das licenciaturas e a formação docente, de um modo geral, tem sido insuficientes para o conhecimento aprofundado desse debate, constituindo-se como um grande desafio no processo pedagógico. Por essa falta, muitas/os das/os profissionais atuam de forma desprevenida e, diante das dificuldades e anseios de estudantes, buscam responder às demandas, mas com ferramentas insuficientes (Seffner, 2013; Silva, 2019).

Nossas/os interlocutoras/es fazem parte de outras redes que as/os possibilitaram acessar conteúdos que não são priorizados no/pelo colégio. Participam de organizações culturais, estudantis, partidos e outros movimentos sociais que facilitam experiências diversas e as/os colocam em contato com pessoas e contextos distintos daqueles que não faziam parte de suas rotinas. Dentro desses movimentos existem momentos para discutir e trabalhar questões da sexualidade, racismo e cultura afro-brasileira, por exemplo. Em nossos encontros sempre relatavam sobre importantes debates realizados nesses ambientes. Nesse sentido, entendemos que esses espaços não formais de educação (Torres, 2013) são importantes para a constituição de cidadanias.

Voltando ao diálogo acima, as/os jovens expõem os limites que professoras/es teriam em lidar com questões da diversidade se elas aparecessem no debate da escola. A partir da situação disparadora do Grupo de Discussão que relatava a situação de uma aluna transexual, João assinala que elas/es nunca tiveram contato com uma/um estudante transexual ou travesti lá dentro e que não dava para saber como a história apresentada se desenvolveria no contexto delas/es, mas todas/os concordaram que os discursos não poderiam ir além do padrão binário da sexualidade: entre o normal e o anormal, o lícito e o ilícito, o masculino e o feminino.

Evidenciou-se, portanto, que as aulas de biologia (disciplina comumente responsável por fazer esse debate) reproduzem o viés biomédico que demarca os discursos de gênero e sexualidade. Assim, a educação sexual se resume em aprender sobre doenças e métodos contraceptivos, reforçando o caráter perigoso da sexualidade. Nessas situações, as/os jovens relatam que elas/es e outras/os colegas até tentam debater sobre outras dimensões da sexualidade, inserindo questionamentos que fujam à norma heterossexual, quando surge a oportunidade de fazer perguntas durante a aula, mas são barradas/os pelas/os professoras/es ou pelas/os outras/os colegas de classe. 
Como sabemos, fazer esse debate quase sempre implica o surgimento de situações difíceis, às vezes polêmicas, marcadas por interditos e preconceitos que dificultam e barram a construção de uma proposta emancipatória e democrática. Segundo Furlani (2013), a interrupção de momentos formais da discussão sobre sexualidade desmotiva as/os jovens e lhes causa sensação de fraude pedagógica, quer seja pela incapacidade de a/o docente trabalhar a temática, quer pela falta de apoio institucional, e pode dificultar a reflexão crítica. Esse era o sentimento das/os meninas/os nos relatos sobre as aulas de biologia.

Outro aspecto trazido durante essa discussão foi a dificuldade de tratar dessas temáticas de modo livre, reconhecendo-as como parte das experiências de todas/os. Elas/es relatam uma sensação de vigilância quando toda e qualquer pessoa ousa pronunciar a diversidade na escola. Segundo as/os jovens, as pessoas começam a olhar com desconfiança e analisar quaisquer sinais que indicam alguma diferença. Assim, uma professora, um professor ou estudante pode se sentir constrangida/o e amedrontada/o ao tentar falar sobre grupos ou práticas sexuais não hegemônicas, como podemos observar no trecho abaixo:

Tâm: Inclusive a nossa ex-professora de biologia, assim, é porque a pessoa, querendo ou não, acaba julgando pelo estereótipo, né? ... eu acho que ela é lésbica, mas ela nunca disse pra ninguém... ela foi dar uma aula de biologia sobre genética e aí ela botou a discussão pra turma se homossexualidade era genético ou não, mas daí quando o negócio ia começar a esquentar ela mesma não teve coragem de continuar aquele debate...

João: Aí ficou só reproduzindo o que é regrado, o assunto que tava no livro...

Tâm: Daí se ela falasse isso, iam dizer que ela só tava falando isso porque é lésbica, porque se fosse hetero não tava trazendo isso pra sala. Sendo que na ementa todinha, todo o assunto é heterossexual, da ementa inteira um assunto que ela ia puxar que não era, todo mundo ia apontar o dedo pra ela depois...

Dessa forma, por meio do silenciamento ou afirmação, a escola exerce uma pedagogia sobre a sexualidade que mantém certa hierarquia por meio de práticas de vigilância que pairam como uma ameaça sob todas e todos (Junqueira, 2010; Louro, 2013b). Diante do exposto, as discussões de gênero e diversidade sexual só aparecem na escola para marcar aquilo que é diferente.

As/Os jovens quando pensaram em diversidade sexual associaram, quase que automaticamente, a pessoas lésbicas, gays e transexuais. Para Louro (2013b), o lugar do excêntrico é ocupado por aquelas/es que fogem à posição central que se hegemoniza e ganha o lugar de natural, fazendo com que as outras posições de sujeitas/os estejam a elas subordinadas. Nesse sentido, entendemos diversidade sexual como todas as expressões de orientação sexual e identidade de gênero possíveis, sexualidades, no plural, que vão além do padrão da heteronormatividade, incluindo as heterossexualidades, homossexualidades, bissexualidades e transexualidades, por exemplo (Torres, 2013).

Essa conversa em torno da diversidade se seguiu também sob o debate de gênero, onde as/os jovens pensaram na transfobia que pessoas transexuais e travestis podem passar na escola. Durante a realização dos grupos, tentamos identificar quais as implicações relacionadas às identidades de gênero presentes em seus cotidianos. Entre as problemáticas compartilhadas elas/es apontam o "abandono" escolar como uma das mais fortes e prejudiciais. 
Léo: ... a minha família em peso fala que a minha irmã trans nunca vai arrumar um emprego, que ela é uma vagabunda... E não é porque ela não tem, não teve escolaridade, ela desistiu muito cedo e não tem opção de emprego, porque ela não tem essa facilidade que uma pessoa cis...

João: E os preconceitos da sociedade evitam isso porque é difícil uma pessoa, a trans, por exemplo, você ter contato com uma pessoa trans na escola porque ela não tem a oportunidade nem de entrar na escola ou de permanecer...

No Brasil, há inúmeras ações para auxiliar na inclusão de pessoas transexuais e travestis nas políticas públicas, como por exemplo a adoção do nome social nos diversos âmbitos sociais que buscam diminuir os impactos das violências sofridas por essa população. Segundo Luma Andrade (2012), a maioria dos discursos produzidos na escola, por professoras/es, gestoras/es e estudantes colocam travestis e transexuais à margem da instituição, obrigando-as/os, muitas vezes, a abandonar a vida escolar e ainda levarem a culpa. Podemos alargar essa compreensão para todas as outras pessoas que fogem aos padrões da heteronormatividade, como lésbicas e gays, por exemplo. Claro, travestis e transexuais sofrem muito mais por causa da negação de seus corpos e identidades. Nesse sentido, Bento (2011) aponta que há um processo de expulsão e não de evasão e é importante diferenciarmos esses dois processos, uma vez que ao apontar com precisão as causas que levam crianças a deixarem de frequentar o espaço escolar poderemos enfrentar com eficácia os dilemas que constituem o cotidiano da escola, entre eles, a intolerância alimentada pelo preconceito homofóbico.

A homossexualidade ou qualquer outro comportamento que questione a norma heterossexual torna as pessoas alvo da vigilância e, nesse sentido, do aumento de controle das normas da escola. Na fala de Léo, quando a instituição reconhece esses comportamentos, “...nós, meio que perdemos a identidade na escola... Você não é o Leonilson, você é o viado da escola”. Assim, qualquer ação das/os sujeitas/os virá acompanhada dos olhares atentos e julgamentos de todas/os, mesmo que isso não esteja implicado na orientação sexual dessas pessoas. Para Louro (2013a), o que efetivamente incomoda é a manifestação pública de comportamentos não-heterossexuais, que destoam e questionam os padrões do feminino e do masculino. O que leva, por outro lado, a algumas pessoas se esconderem, sob a ameaça constante de serem descobertas, e até imitarem os comportamentos da norma heterossexual, ainda que seus desejos sejam suprimidos.

Brunna: E a gente sabe que a maioria da galera que tá aqui dentro vai sair daqui muito preconceituosa ... Pessoas, inclusive, que são LGBTs mas que reproduzem o preconceito. Enfim, que nunca vão ter coragem de se assumir.

João: Tenho um amigo que já ficou com um menino aqui dentro e ele é cheio daquelas piadinhas, tá ligado? ...

Léo: Ele anda com LGBTfóbicos porque ele acha que é uma maneira de dizer - "Ah, eu não sou”. 
Dessa forma, mantendo suas sexualidades em segredo, dentro de um armário, essas pessoas podem ficar livres da vigilância e dos julgamentos da norma, ainda que seja mais uma forma de invisibilização e apagamento da diversidade sexual. De acordo com Prado, Nogueira, e Martins (2012, p. 40), “o armário impediria assim, a emergência do conflito coletivo na cena pública, ao mesmo tempo que serve de arma para a resolução (ou o contorno, o desvio) desses mesmos conflitos em nível local e individual”. Portanto, as/os jovens reconhecem que esse tipo de atitude pode ser considerado aceitável para as pessoas que precisam ou querem manter sua sexualidade em segredo, uma vez que elas/es entendem que na escola é muito difícil assumir comportamentos que desafiam as normas, desde que não humilhem as outras pessoas que, em alguns casos, nem tiveram o direito de escolher revelar ou não suas sexualidades.

\section{Considerações finais}

Neste trabalho, buscamos apreender as múltiplas facetas da relação entre espaço escolar, gênero e sexualidade em um cenário marcado por normas e regulações, por potências e (ainda poucas) rupturas, com a finalidade de entender, a partir da visão das/ os estudantes quais sentidos atribuíam a essa relação. Desse modo, discutimos ao longo do texto como e quais roteiros sexuais são possibilitados dentro da escola e que estratégias podem ser pensadas para avançarmos no debate da diversidade.

De um modo geral, as regras disciplinares do gênero e da sexualidade estiveram e estão presentes em todos os espaços da escola. As discussões apresentadas podem ser aplicadas facilmente em outras instituições. Quer sejam escolas de ensino médio, quer sejam de ensino fundamental e até na universidade encontraremos exemplos semelhantes. Essa dimensão do controle e da norma é algo amplamente discutido em trabalhos que investigam as relações entre gênero, sexualidade e educação.

Em nossa pesquisa, vimos estudantes que com suas diferentes culturas e inserções, têm, com limites e muitos desafios, questionado uma outra forma de ocupar os espaços dentro da escola e reivindicar o debate em torno do gênero e da sexualidade dentro da instituição. A partir de seus questionamentos, a escola tem a possibilidade de produzir um outro movimento, de maior fluidez, onde encontros e espaços são construídos e direcionam nossos olhares para outra produção de saberes e ações que provocam pequenas fissuras no interior da instituição.

Observamos que as redes de movimentos acessadas pelas/os estudantes têm sido fundamentais no processo de propor e demandar da escola um outro olhar para esse debate. Afirmam atrizes e atores que no cotidiano, na realização de atividades, no questionamento em sala de aula, nas pontuações e conversas entre elas/es, exercitam e exercem práticas de rupturas com o instituído em termos de interdição e controle. São jovens que rearranjam os espaços institucionais e colaboram para transformar a escola em um espaço democrático e de constante disputa. Em particular, as atividades desenvolvidas por essas/es estudantes têm uma potência enorme em questionar a dureza das normas presentes na escola, revelando seu caráter desigual e não natural. 
Compreendemos a escola como um espaço em disputa, lugar de múltiplas vozes. Ao trazermos as e os estudantes como sujeitos centrais dessa pesquisa para pensar como as questões de gênero e sexualidade atravessam as práticas escolares, observamos a importância do envolvimento de algumas/uns professoras/es na realização de atividades que mobilizem a reflexão em torno desses temas. No entanto, nos parece imprescindível o investimento na formação docente, seja nas licenciaturas, seja em uma formação continuada de professoras/es que as/os instrumentalize, e amplie os horizontes para uma educação crítica com foco neste debate. Muitas/os delas/es ou se sentem despreparadas/ os, sem saber ao certo como abordar questões trazidas pelas/os estudantes, ou ainda são fortemente atravessadas/os por uma visãoe práticas heteronormativas que dificultam ou impedem uma intervenção qualificada.

Nesse contexto, percebemos a construção de uma crítica por parte destas/es jovens às dinâmicas escolares que não dialogam com suas experiências afetivas, com o cotidiano de relações mais abertas que exercitam, praticam. A reivindicação do debate de gênero e da sexualidade de uma forma aberta e com a participação de todas/os, diz muito da importância que a escola ocupa em suas vidas, uma vez que elas/es pleiteiam uma educação mais próxima de suas realidades e experiências.

Vivemos em uma época em que os discursos e ideologias de uma parcela conservadora da sociedade tentam retroceder muitas conquistas no âmbito das lutas associadas ao gênero e à sexualidade. Quando pensamos no espaço escolar, ficam visíveis as disputas em torno das políticas que dão visibilidade a esses temas como eixos de uma educação inclusiva. A existência de um projeto como o Escola Livre, que tem como cerne de sua intervenção, o silenciamento do debate, a penalização de quem o faz, e a terceirização deste tipo de formação para instituições como a família e a igreja, sinaliza a necessidade de fortalecer no âmbito da educação os pontos de mobilização, resistência e luta.

No entanto, muitas/os jovens evidenciam a centralidade da escola nas construções de suas subjetividades, fazendo-nos questionar o papel da educação. Ocupações, passeatas e muitas outras formas criativas de mobilização têm colocado na cena pública as questões plurais das juventudes. As questões trazidas neste artigo nos permitem refletir sobre a necessidade de uma educação que possa estar comprometida com a diversidade de gênero e sexual enquanto características constitutivas das/os sujeitas/os, incorporando uma visão crítica dos limites políticos impostos na contemporaneidade. 


\section{Notas}

1 A utilização de marcadores como a/o, as/os ao longo do texto tem sido uma prática em textos que discutem gênero, principalmente por parte de autoras/es feministas. Adotaremos esse estilo por concordarmos que essa política de escrita torna a linguagem menos sexista.

2 Ver, por exemplo, Bracke e Paternotte (2016), Corrêa (2017), Garbagnoli (2016), e Junqueira (2018, 2019).

3 O termo 'cis' é um termo político em disputa, que se refere a afirmação e diferenciação com o termo 'trans', que trata de questões sobre e para a população transexual e travesti. A expressão heteronormatividade refere-se à produção e reiteração compulsória da norma heterossexual.

4 De modo geral, investigadoras/es costumam usar nomes fictícios para preservar as identidades de suas/seus informantes. No caso desta pesquisa, os nomes utilizados são os de registro e, em muitas vezes, apelidos pelos quais as/os jovens são conhecidas/os. O uso foi autorizado após a leitura do TCLE, onde as/os próprias/os jovens questionaram a necessidade do sigilo, permitindo assim que usemos suas identidades. 


\section{Referências}

Abramovay, M., Castro, M. G., \& Silva, L. B. (2004). Juventude e Sexualidade. Brasília, DF: UNESCO Brasil.

Andrade, L. N. (2012). Travestis na escola: assujeitamento e resistência à ordem normativa. Tese de Doutorado, Programa de Pós-graduação em Educação, Universidade Federal do Ceará, Fortaleza, CE.

Bento, B. (2011). Na escola se aprende que a diferença faz a diferença. RevistaEstudosFeministas, 19(2), 549-559.

Bracke, S. \& Paternotte, D. (2016). Unpaking the Sin of Gender. Religion \& Gender, 6(2), 143-154. doi.org/10.18352/rg.10167. Recuperado de https://brill.com/view/journals/rag/6/2/ article-p143 1.xml

Butler, J. (2015). Problemas de gênero: feminismo e subversão da identidade. Rio de Janeiro: Civilização Brasileira.

Campos, C. J. G. (2004). Método de análise de conteúdo: ferramenta para a análise de dados qualitativos no campo da saúde. Revista Brasileira de Enfermagem, 57(5), 611-614.

Castro, L. R. (2012). Entre a subordinação e a opressão: os jovens e as vicissitudes da resistência na escola. In C. Mayorga, L. R. Castro, \& M. A. M. Prado (Orgs.), Juventude e a experiência da política no contemporâneo (pp. 63-97). Rio de Janeiro: Contra Capa.

Chauí, M. (2003). A universidade pública sob nova perspectiva. Revista Brasileira de Educação, 24, 5-15.

Corrêa, S. (2017). “Ideologia de gênero": rastros perdidos e pontos cegos. Recuperado de https://www.youtube.com/watch?v=VWBj6GX2Umo\&feature=youtu.be

Facchini, R. (2005). Sopa de letrinhas? Movimento homossexual e produção de identidades coletivas nos anos 1990. Rio de Janeiro: Garamond.

Furlani, J. (2013). Educação sexual: possibilidades didáticas. In G. L. Louro, J. Felipe, \& S. V. Goellner (Orgs.), Corpo, gênero e sexualidade: um debate contemporâneo na educação (pp. 67-82). Petrópolis/RJ: Vozes.

Garbagnoli, S. (2016). Against the Heresy of Immanence: Vatican's “Gender" as a New Rhetorical Device against the Desnaturalisation of the Sexual Order. Religion\&Gender, 6 (2), 187 204. doi.org/10.18352/rg.10156. Recuperado de https://brill.com/view/journals/rag/6/2/articlep187 4.xml

Junqueira, R. D. (2009a). Homofobia nas escolas: um problema de todos. In Diversidade Sexual na Educação: problematizações sobre homofobia nas escolas (pp. 13-51). Brasília, DF: Ministério da Educação.

Junqueira, R. D. (2009b). Currículo Heteronormativo e cotidiano escolar homofóbico. Espaço do Currículo, 2(2), 208-230.

Junqueira, R. D. (2010). "A homofobia não é um problema. Aqui não há gays nem lésbicas!" Estratégias discursivas e estado de negação da discriminação por orientação sexual e identidade de gênero nas escolas. Revista de Psicologia da UNES, 9(1), 123-139.

Junqueira, R. D. (2018). A invenção da "ideologia de gênero": a emergência de um cenário político-discursivo e a elaboração de uma retórica reacionária antigênero. Revista Psicologia Política, 18(43), 449-502.

Junqueira, R. D. (2019). O discurso reacionário antigênero e a educação. In F. A. Costa \& M. R. Mesquita (Orgs.), Psicologia Política no Brasil e enfrentamentos a processos antidemocráticos (pp. 159-180). Maceió: EDUFAL. 
Lincoln, Y. S. \& Guba, E. G. (2006). Controvérsias paradigmáticas, contradições e confluências emergentes. In N. K. Denzin, Y. S. Lincoln (Orgs.), O planejamento da pesquisa qualitativa: teorias e abordagens (pp. 169-192). Porto Alegre: Bookman e Artmed.

Lionço, T. (2016). Criminalização do assédio ideológico nas escolas: ideologia de gênero como argumento central na disputa fundamentalista da política de educação. In A. Rodrigues, G. Monzeli, \& S. R. Ferreira (Orgs.), A política do corpo - gênero e sexualidade em disputa (pp. 145-160). Vitória: EDUFES.

Louro, G. L. (1997). Gênero, sexualidade e Educação: uma perspectiva pós estruturalista. Petrópolis/RJ: Vozes.

Louro, G. L. (2013a). Pedagogia da sexualidade. In O corpo educado: pedagogias da sexualidade (pp. 07-34). Belo Horizonte: Autêntica.

Louro, G. L. (2013b). Currículo, gênero e sexualidade - o "normal", o "diferente" e o "excêntrico". In G. L. Louro, J. Felipe, \& S. V. Goellner (Orgs.), Corpo, gênero e sexualidade: um debate contemporâneo na educação (pp. 43-53). Petrópolis/RJ: Vozes.

Machado, F. V. (2007). Muito além do arco-íris. A construção de identidades coletivas entre sociedade civil e o Estado. Dissertação de Mestrado, Programa de Pós-graduação em Psicologia, Universidade Federal de Minas Gerais, Belo Horizonte, MG.

Maia, M. B. (2007). Gênero: um conceito em movimento. In C. Mayorga \& M. A. M. Prado (Orgs.), Psicologia Social: articulando saberes e fazeres (pp. 133-141). Belo Horizonte: Autêntica.

Mattos, A. R. (2012). Liberdade, um problema do nosso tempo: os sentidos de liberdade para os jovens no contemporâneo. Rio de Janeiro: Editora FGV.

Méndez, M. G. C. (2007). El grupo de discusión: una estrategia metodológica para generar conocimiento reflexivo en la investigación social desde la perspectiva cualitativa. Colima, México: Universidadde Colima.

Neves, S. \& Nogueira, C. (2004). Metodologias feministas na psicologia social crítica: a ciência ao serviço da mudança social. ExAequo, 11, 123-138.

Prado, M. A. M., Nogueira, P. H., \& Martins, D. A. (2012). Escola e política do armário na produção e reprodução das hierarquias sexuais no Brasil. In A. Rodrigues \& M. A. S. C. Barreto (Orgs.), Currículos, gêneros e sexualidades: experiências misturadas e compartilhadas (pp. 165-182). Vitória: EdUFES.

Rancière, J. (1996). O desentendimento: política e filosofia. São Paulo: Ed. 34.

Scott, J. (1995). Gênero: uma categoria útil de análise histórica. Revista Educação \& Realidade, 20(2), 71-99.

Seffiner, R. (2013). Sigam-me os bons: apuros e aflições nos enfrentamentos ao regime da heteronormatividade no espaço escolar. Educação e Pesquisa, 39(1), 145-159.

Silva, J. H. (2019). Gênero e sexualidade no cotidiano escolar sob a perspectiva de professoras e professores. Dissertação de Mestrado, Programa de Pós-graduação em Psicologia, Universidade Federal de Alagoas, Maceió, AL.

Torres, M. A. (2012). A emergência de professoras travestis e transexuais na escola: heteronormatividade e direitos nas figurações sociais contemporâneas. Tese de Doutorado, Programa de Pós-graduação em Psicologia, Universidade Federal de Minas Gerais, Belo Horizonte, MG.

Torres, M. A. (2013). A diversidade sexual na educação e os direitos de cidadania LGBT na escola. Belo Horizonte: Autêntica. 


\section{JULIANO BONFIM}

\section{https://orcid.org/0000-0001-8721-1182}

Estudante de Doutorado no Programa de Pós-graduação em Psicologia da Faculdade de Filosofia e Ciências Humanas da Universidade Federal de Minas Gerais.

Endereço: Faculdade de Filosofia e Ciências Humanas da Universidade Federal de Minas Gerais - Av. Pres. Antônio Carlos, 6627 - Pampulha, Belo Horizonte - MG, CEP $31270-901$.

E-mail: bonfimjuliano@yahoo.com.br

\section{MARCOS RIBEIRO MESQUITA}

\section{https://orcid.org/0000-0002-1642-0259}

Doutor em Psicologia pela Pontifícia Universidade Católica de São Paulo. Professor do Programa de Pós-graduação do Instituto de Psicologia da Universidade Federal de Alagoas, Maceió.

E-mail: marcosmesquita@hotmail.com

\begin{tabular}{|c|c|}
\hline \multirow{3}{*}{ Histórico } & Submissão: 16/04/2018 \\
\hline & Revisão: 18/02/2020 \\
\hline & Aceite: 23/03/2020 \\
\hline \multirow{6}{*}{ Contribuição dos autores } & Concepção: JB; MRM \\
\hline & Coleta de dados: JB \\
\hline & Análiise de dados: JB; MRM \\
\hline & Elaboração do manuscrito: JB; MRM \\
\hline & $\begin{array}{l}\text { Crítico revisões de conteúdo intelectual importante: } \\
\text { MRM }\end{array}$ \\
\hline & Aprovação final do manuscrito: JB; MRM \\
\hline Consentimento de uso de imagem & Não se aplica. \\
\hline Aprovação, ética e consentimento & $\begin{array}{l}\text { O estudo foi aprovado pelo CEP da UFAL em } 15 \text { de } \\
\text { janeiro de } 2015 \text {, sob número de parecer } 931.708 \text {; } \\
\text { CAAE: } 40102714.0 .0000 .5013 \text {. }\end{array}$ \\
\hline Financiamento & $\begin{array}{l}\text { Bolsa de Mestrado concedida pela CAPES; Edital } \\
\text { O1/2014 do Programa de Pós-Graduação em Psicologia } \\
\text { da UFAL. }\end{array}$ \\
\hline
\end{tabular}

